\title{
Fluid management in ARDS: an evaluation of current practice and the association between early diuretic use and hospital mortality
}

\author{
Kevin P. Seitz ${ }^{1,2^{*}}$ (D) Ellen S. Caldwell ${ }^{3}$ and Catherine L. Hough ${ }^{4}$
}

\begin{abstract}
Background: Acute respiratory distress syndrome (ARDS) and volume overload are associated with increased hospital mortality. Evidence supports conservative fluid management in ARDS, but whether current practice reflects the implementation of that evidence has not been described. This study reports the variability in contemporary fluid management for ICU patients with ARDS. We compared routine care to trial protocols and analyzed whether more conservative management with diuretic medications in contemporary, usual care is associated with outcomes.

Methods: We performed a retrospective cohort study in nine ICUs at two academic hospitals during 2016 and 2017. We included 234 adult patients with ARDS in an ICU at least 3 days after meeting moderate-severe ARDS criteria $\left(\mathrm{PaO}_{2}\right.$ : $\mathrm{FIO}_{2} \leq 150$ ). The primary exposure was any diuretic use in 48 to $72 \mathrm{~h}$ after meeting ARDS criteria. The primary outcome was hospital mortality. Unadjusted statistical analyses and multivariable logistic regression were used.

Results: In 48-72 h after meeting ARDS criteria, 116 patients (50\%) received a diuretic. In-hospital mortality was lower in the group that received diuretics than in the group that did not (14\% vs 25\%; $p=0.025)$. At ARDS onset, both groups had similar Sequential Organ Failure Assessment scores and ICU fluid balances. During the first $48 \mathrm{~h}$ after ARDS, the diuretic group received less crystalloid fluid than the no diuretic group (median [inter-quartile range]: 1.2 L [0.2-2.8] vs $2.4 \mathrm{~L}[1.2-5.0] ; ;<0.001)$, but both groups received more fluid from medications and nutrition than from crystalloid. At $48 \mathrm{~h}$, the prevalence of volume overload (ICU fluid balance $>10 \%$ of body weight) in each group was $16 \%$ and $25 \%(p=0.09)$, respectively. During 48-72 h after ARDS, the overall prevalence of shock was $44 \%$ and similar across both groups. Central venous pressure was recorded in only $18 \%$ of patients. Adjusting for confounders, early diuretic use was independently associated with lower hospital mortality (AOR 0.46, 95\% $[0.22,0.96]$ ).

Conclusions: In this sample of ARDS patients, volume overload was common, and early diuretic use was independently associated with lower hospital mortality. These findings support the importance of fluid management in ARDS and suggest opportunities for further study and implementation of conservative fluid strategies into usual care.
\end{abstract}

Keywords: Acute respiratory distress syndrome, Diuretics, Fluid therapy, Critical care

\footnotetext{
*Correspondence: kevin.seitz@vumc.org

This work was performed at the University of Washington in Seattle, WA.

'Division of Pulmonary, Allergy, and Critical Care Medicine, Vanderbilt University, Nashville, TN, USA

Vanderbilt University Medical Center, T1218 MCN, 1161 21st Avenue, Nashville, TN 37232, USA

Full list of author information is available at the end of the article
}

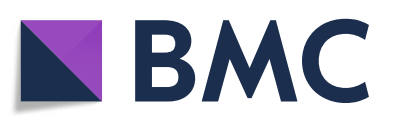

(c) The Author(s). 2020 Open Access This article is licensed under a Creative Commons Attribution 4.0 International License, which permits use, sharing, adaptation, distribution and reproduction in any medium or format, as long as you give appropriate credit to the original author(s) and the source, provide a link to the Creative Commons licence, and indicate if changes were made. The images or other third party material in this article are included in the article's Creative Commons licence, unless indicated otherwise in a credit line to the material. If material is not included in the article's Creative Commons licence and your intended use is not permitted by statutory regulation or exceeds the permitted use, you will need to obtain permission directly from the copyright holder. To view a copy of this licence, visit http://creativecommons.org/licenses/by/4.0/. The Creative Commons Public Domain Dedication waiver (http://creativecommons.org/publicdomain/zero/1.0/) applies to the data made available in this article, unless otherwise stated in a credit line to the data. 


\section{Background}

Acute respiratory distress syndrome (ARDS) is a lifethreatening condition marked by hypoxemic respiratory failure and non-cardiogenic pulmonary edema $[1,2]$. Despite decades of focused research, ARDS remains common in critically ill patients and is associated with high mortality $[3,4]$. In the management of patients with ARDS, the accumulation of a positive fluid balance has been associated with increased duration of mechanical ventilation and mortality, but fluid balance is a potentially modifiable risk factor for these poor outcomes [5-10].

With the Fluids and Catheters Treatment Trial (FACT T) in 2007, Wiedemann and collaborators demonstrated that a conservative fluid management strategy for ARDS reduces net fluid balance and improves outcomes in oxygenation and ventilator-free days [11]. The trial used a protocol guided by the central venous pressure (CVP) or pulmonary artery occlusion pressure (PAOP) to increase the use of diuretic medication and decrease the use of intravenous crystalloid. The protocol instructions established probable best practices for fluid management in ARDS [12-15]. These findings were supported further by a subsequent, less strict protocol (FACTT Lite) that also was associated with improved outcomes [16].

Despite the substantial body of evidence that positive fluid balance or volume overload could be harmful and that conservative fluid management may confer a benefit, few studies have characterized fluid balance in ARDS populations outside of clinical trials [8, 17]. It is not known whether conservative strategies, like early administration of diuretics, are used routinely in current practice for ARDS patients or whether they are associated with better outcomes when implemented in usual care.

This study describes the variability in fluid management among patients with moderate-severe ARDS in the intensive care unit (ICU). Specifically, we compare outcomes in patients who do and do not receive diuretic medications 48 to $72 \mathrm{~h}$ after meeting ARDS criteria, adjusting for clinical factors like severity of illness. We obtained empiric data about fluid balance and diuretic use in ARDS, and we hypothesized that early diuretic use would be independently associated with hospital mortality.

\section{Methods}

\section{Study design}

We conducted a retrospective cohort study of patients admitted to nine ICUs at two academic hospitals in Seattle, Washington from October 2016 to March 2017. We included all patients that had acute respiratory failure requiring intubation and mechanical ventilation in the ICU with moderate-severe ARDS as defined by a $\mathrm{PaO}_{2}$ : $\mathrm{FiO}_{2}$ ratio $\leq 150$ with bilateral opacities on chest imaging not fully explained by cardiac failure, lung collapse, nodules, or effusions [2]. Patients with chronic tracheostomies or admissions only for dialysis were excluded.

Patients were included from all ICUs in the two participating hospitals. Patients in these units are cared for by teaching services led by attending physicians with trainees. Daily rounds are practiced in all units with variability in processes of care like daily weights, and no protocols are in use for ARDS fluid management.

To capture the diversity of patients with ARDS as defined by evidence-based criteria, we excluded only those who first met ARDS criteria at an outside hospital and those who required renal replacement therapy, died, or were discharged from the ICU prior to $72 \mathrm{~h}$ after meeting ARDS criteria. Using the Berlin definition for ARDS, we did not exclude patients with a diagnosis of heart failure unless they also lacked an ARDS risk factor.

Data were abstracted from the electronic medical record by both automated methods and manual chart review for every patient. The institutional review board at the University of Washington reviewed and approved this study, waiving the need for informed consent.

\section{Primary variables}

The primary outcome of interest was hospital mortality. Secondary outcomes were duration of mechanical ventilation and disposition at hospital discharge. Our primary exposure of interest was early diuretic use, defined as any diuretic use 48 to $72 \mathrm{~h}$ after meeting ARDS criteria. This time interval corresponds approximately to the first day of protocolized management in the FACTT trial, where enrollment was permitted up to $48 \mathrm{~h}$ after acute lung injury [11]. The secondary exposure of conservative fluid management was defined as the restrictive use of intravenous crystalloid fluids with less than $500 \mathrm{~mL}$ in that same 24-h period.

\section{Covariates}

We collected patient demographics and clinical characteristics as covariates. Demographics included gender, race, age, and admission body weight. Clinical characteristics present at ARDS included chronic comorbidities, ARDS risk factors like trauma or sepsis as documented, and ICU admission directly from the operating room, ICU fluid balance before ARDS, and the Sequential Organ Failure Assessment (SOFA) score at the onset of ARDS [18].

The following clinical factors at 48 to $72 \mathrm{~h}$ after ARDS were defined a priori and evaluated as potential confounders because they were present at the time of diuretic management decisions and are known to be associated with mortality: shock, acute kidney injury (AKI), and persistently severe ARDS. Shock was defined as vasopressor use or mean arterial pressure $<60 \mathrm{mmHg}$ for two measurements. AKI was defined serum creatinine $\geq 2 \mathrm{mg} / \mathrm{dL}$ or oliguria (urine output $<500 \mathrm{~mL}$ in $24 \mathrm{~h}$ ) 
using criteria for renal failure established by the SOFA score for comparison with future studies. Persistently severe ARDS was defined by $\mathrm{PaO}_{2}: \mathrm{FiO}_{2} \leq 150$. Relevant electrolyte derangements were defined as any serum potassium $<3$ $\mathrm{mEq} / \mathrm{L}$, sodium $>150 \mathrm{mEq} / \mathrm{L}$, or bicarbonate $>40 \mathrm{mEq} / \mathrm{L}$.

Volume overload was defined by an ICU fluid balance of more than $10 \%$ of the hospital admission weight, as established by previous studies [19-22]. Daily fluid intake was characterized as crystalloid, free water, medication fluid, nutrition, and transfusions. Crystalloid includes any intravenous fluid containing sodium chloride or lactated Ringer's solution given as boluses or continuous maintenance infusions not specified as medications or piggybacks. Admission weight was abstracted from the earliest weight recorded in an approach similar to prior studies, measured on a bed scale either in the Emergency Department or on arrival to the ICU [21]. Missing laboratory and physiologic values for the time periods of interest were assumed to be normal.

\section{Statistical analysis}

Descriptive statistics were computed for ICU and patient characteristics. Covariates were plotted to explore distributions and suitable categorizations for statistical modeling. Differences in baseline characteristics by diuretic use were explored in bivariate analyses using Student's $t$ tests, Wilcoxon rank-sum tests, and chi-square tests as appropriate. To confirm clinical eligibility for diuretic use across groups, we also assessed for differences in physiological variables (shock, AKI, CVP, electrolyte derangements) used in the FACTT conservative strategy protocol for which clinicians were instructed against or permitted exceptions to diuretic use [11].

We used several approaches to evaluate the associations between fluid balance, diuretic use, and hospital mortality. Cumulative ICU fluid balance over time, hospital mortality, and liberation from mechanical ventilation were plotted over time by diuretic use at ARDS hours 48 to 72 . Volume overload at $48 \mathrm{~h}$ was a clinically meaningful measure of fluid balance and treated as a confounding factor associated with both diuretic use and hospital mortality. Similarly, the use of minimal crystalloid fluid is likely to be associated with early diuretic use and was considered a potential confounder.

Multivariable logistic regression was performed to evaluate the associations between early diuretic use and hospital mortality controlling for confounders identified a priori. In the final multivariable model, we included age, SOFA score at ARDS onset, heart failure, trauma status, volume overload at $48 \mathrm{~h}$ after ARDS, and shock at 48 to $72 \mathrm{~h}$. Crystalloid use and shock were not included, due to high collinearity with other exposures.

Sensitivity analyses were performed by assessing for effect-modification with each confounder. We also repeated the analyses stratifying by potentially influential subgroups-sepsis, ICU type, history of heart failure, and FACTT protocol instructions-to explore the robustness of results. Analyses were conducted using SAS version 9.4 (Cary, NC).

\section{Results}

Four hundred and twenty-seven patients were screened for inclusion with qualifying respiratory failure and chest imaging during the study period (Fig. 1). Of these, 388 patients met moderate-severe ARDS criteria. From these eligible patients, 234 were alive in the ICU at $72 \mathrm{~h}$ after meeting ARDS criteria, did not receive early renal replacement therapy, and were included in this analysis. Most patients in this sample were in the hospital 1 day or less before developing ARDS, and for most patients, mechanical ventilation was initiated on the same day that they met ARDS criteria (Table 1). Between 48 and $72 \mathrm{~h}$ after ARDS, $50 \%$ of the patients received a dose of diuretic medication. Of the patients who received diuretics, 108 (93\%) received furosemide, six $(5 \%)$ of the remaining patients received bumetanide and two (2\%) received only diuretics other than loop diuretics. The median cumulative furosemide dose over $24 \mathrm{~h}$ was $40 \mathrm{mg}$ (interquartile range: [20-80 mg]) (Supplemental Table 1).

Demographics were similar across groups with and without diuretic. The patients receiving diuretics had a higher prevalence of chronic congestive heart failure, and they were more often in the cardiothoracic ICU and less often in medical ICUs. Fewer patients receiving diuretics had trauma as an ARDS risk factor, but both groups had similar proportions of patients with sepsis. At the onset of ARDS, both had similar SOFA scores and ICU fluid balances. By hour 72 of ARDS, the groups also had overall similarly high rates of shock (44\%, 95\% CI: [38\%, 51\%]), low rates of AKI $(13 \%,[9 \%, 18 \%])$, and low prevalence of persistently severe ARDS (12\%, [8\%, 16\%]). During ARDS hours 48 to 72, the group that received a diuretic more often had a CVP measurement recorded, but the proportion in both groups was low ( $8 \%$ vs $28 \%, p=0.0001$ ).

\section{Fluid balance}

Both groups had similar net ICU fluid balances prior to ARDS, with median volumes close to zero (Table 2). In the next $48 \mathrm{~h}$, however, those who did not receive diuretics were given approximately twice as much crystalloid fluid on average as those who did (median [interquartile range]: $2.4 \mathrm{~L}$ [1.2-5.0] vs $1.2 \mathrm{~L}$ [0.2-2.8], respectively; $p<0.001$ ). The majority of fluid administered overall was not crystalloid but medication fluids or nutrition. At $48 \mathrm{~h}$ after ARDS, the group that received diuretics had a remarkably lower net fluid balance (Fig. 2). During hours 48 to 72 , most patients received less than $500 \mathrm{~mL}$ of crystalloid, but at $72 \mathrm{~h}$, the difference in median fluid balances 


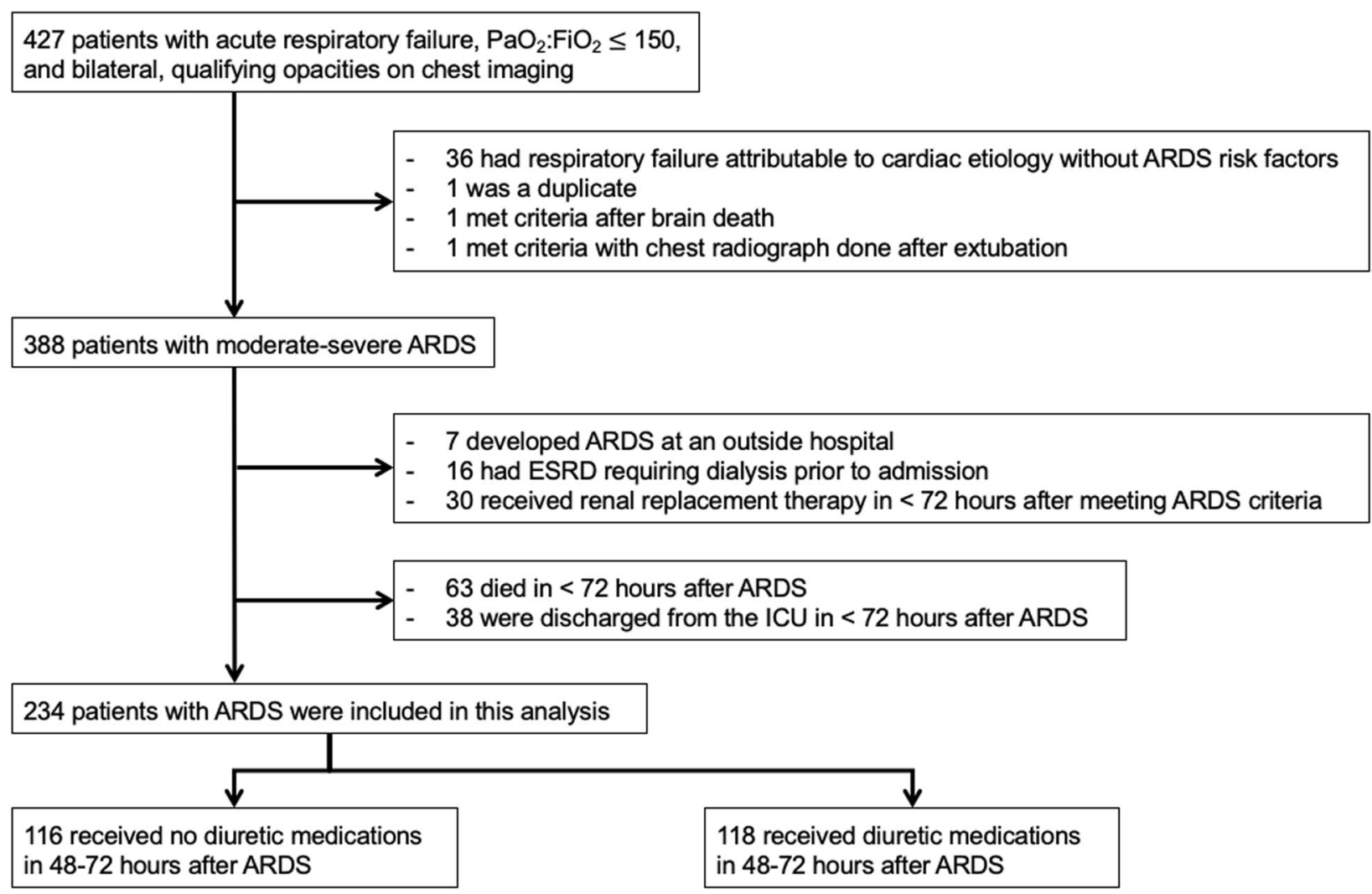

Fig. 1 Study flow chart. ARDS = acute respiratory distress syndrome; ESRD = End-stage renal disease

had increased to $3.7 \mathrm{~L}$ (Supplemental Table 1). At $72 \mathrm{~h}$, the proportion of patients that met volume overload criteria was twice as high in the group that did not receive diuretics compared with those that did (34\%, 95\%CI: $[25 \%, 43 \%]$ vs $16 \%[10 \%, 24 \%] ; p=0.02)$.

\section{Comparing diuretic use to clinical trial protocol}

The FACTT study protocol provided instructions for holding diuretics in renal failure and within $12 \mathrm{~h}$ of shock. During 48-72 $\mathrm{h}$ after ARDS in this cohort, the overall prevalence of acute kidney injury was low (13\%, 19/234) with no difference between groups (Supplemental Table 2). Shock was common in this population overall but was not associated with diuretic use $(47 \%$ in the no diuretic group vs $41 \%$ in the diuretic group; $p=$ 0.42). Protocol instructions also included not giving diuretics to some patients with a CVP $\leq 8 \mathrm{~cm} \mathrm{H}_{2} \mathrm{O}$, and electrolyte derangements were monitored as an adverse outcome. In our cohort, both of these circumstances were very rare. In sum, these clinical factors could represent criteria for not giving diuretics per the FACTT protocol, but we found they were not associated with diuretic use in routine practice $(51 \%$ vs $50 \%$, respectively; $p=0.90$ ).

\section{Outcomes}

Forty-six patients $(20 \%$; $95 \%$ CI: $[15 \%, 25 \%])$ died in the hospital with a higher rate in the group that did not receive early diuretic medications ( $25 \%$ vs $14 \% ; p=0.03$ ) (Fig. 3). In bivariate analyses, age, SOFA score at onset of ARDS, AKI, less than $500 \mathrm{~mL}$ of crystalloid fluid given, and diuretic use during hours 48 to 72 each were associated with hospital mortality (Supplemental Table 3).

A multivariable logistic regression model with confounders chosen a priori was constructed to explore the association between early diuretic use and hospital mortality. In the final model, diuretic use at 48 to $72 \mathrm{~h}$ was independently associated with hospital mortality by an adjusted odds ratio of 0.46 (95\%CI: [0.22, 0.96]), even after controlling for age, SOFA score at onset of ARDS, history of congestive heart failure, trauma status, and volume overload at $48 \mathrm{~h}$ (Table 3). Of note, volume overload at $48 \mathrm{~h}$ was not independently associated with mortality in the multivariable model but has collinearity with diuretic use that did not reach statistical significance.

For secondary outcomes, the differences by diureticuse group in the duration of mechanical ventilation among survivors and in proportion discharged to home self-care were not statistically significant. 
Table 1 Patient characteristics by diuretic exposure in 48-72 $\mathrm{h}$ after meeting acute respiratory distress syndrome criteria

\section{Patient characteristics ${ }^{\mathrm{a}}$ (units)}

No. of patients

\section{Demographics:}

Gender (female)
Race (non-white)
Age (years)
Admission weight (kg)

\section{Comorbidities:}

Congestive heart failure

Chronic lung disease

Cirrhosis

\section{ARDS risk factors:}

Sepsis
Trauma

\section{ICU admission from operating room}

ICU type:

Medical ICU

Cardiothoracic ICU

Trauma-surgical ICU

Other ICU

Prior to ARDS:

$$
\begin{aligned}
& \text { Hospital length of stay (days) } \\
& \text { Mechanical ventilation (days) } \\
& \text { SOFA score, day } 0
\end{aligned}
$$

\section{During ARDS hours 0-48:}

$$
\begin{aligned}
& \text { Shock } \\
& \text { Acute Kidney Injury } \\
& \text { Lowest PaO2:FiO2 } \leq 150 \\
& \text { Any CVP measured } \\
& \text { Any transfusion }
\end{aligned}
$$

Volume overload at $48 \mathrm{~h}$

During ARDS hours 48-72:

Shock
Acute Kidney Injury
Lowest PaO2:FiO2 $\leq 150$
Any CVP measured
Any transfusion
Weight measured
Total furosemide dose ${ }^{c}(\mathrm{mg} / 24 \mathrm{~h})$

$\begin{array}{ll}\text { No diuretic in } \mathbf{4 8 - 7 2} \mathrm{h} \text { after ARDS } & \text { Rec } \\ 118 & 116\end{array}$

$35(30 \%)$
$26(23 \%)$
$56(17)$
$82.5[66.1-104.4]$

$\begin{array}{ll}42(36 \%) & 0.29 \\ 15(13 \%) & 0.07 \\ 57(15) & 0.59 \\ 82.5[70.1-102.4] & 0.63\end{array}$

38 (32\%)

61 (53\%)

0.002

$38(32 \%)$

$37(32 \%)$

0.96

$5(4 \%)$

$4(3 \%)$

0.75

$57(48 \%)$

$55(47 \%)$

0.89

46 (39\%)

26 (22\%)

0.006

$17(14 \%)$

21 (18\%)

0.44

-

37 (31\%)

12 (10\%)

18 (16\%)

33 (28\%)

38 (32\%)

27 (23\%)

31 (26\%)

38 (33\%)

$$
\begin{aligned}
& 1[0-4] \\
& 0[0-1] \\
& 10.3(2.9)
\end{aligned}
$$
1 [0-3.5]
0 [0-1]
$10.5(2.9)$

0.44

0.15

0.64

85 (78\%)

88 (76\%)

0.51

$22(19 \%)$

$118(100 \%)$

15 (13\%)

0.23

24 (20\%)

116 (100\%)

44 (38\%)

0.0031

32 (27\%)

31 (27\%)

0.95

30 (25\%)

19 (16\%)

0.09

55 (47\%)

48 (41\%)

0.42

19 (16\%)

$11(9 \%)$

10 (8\%)

$12(10 \%)$

0.19

16 (14\%)

0.28

$13(11 \%)$

32 (28\%)

0.0001

68 (58\%)
0.1

0.012
85 (73\%)

.29
.07
.59
.63
.002
.96
.75
.89
0.006
0.44

40 [20-80] 
Table 1 Patient characteristics by diuretic exposure in 48-72 h after meeting acute respiratory distress syndrome criteria (Continued)

\begin{tabular}{|c|c|c|c|}
\hline Patient characteristics ${ }^{\mathrm{a}}$ (units) & No diuretic in $48-72 \mathrm{~h}$ after ARDS & Received diuretic in $48-72 \mathrm{~h}$ after ARDS & $P$ value \\
\hline \multicolumn{4}{|l|}{ Outcomes } \\
\hline RRT in first 7 days after ARDS & $5(4 \%)$ & $2(2 \%)$ & 0.26 \\
\hline Duration of MV, all (days) & $7[3-13]$ & $5[3-9]$ & 0.034 \\
\hline Duration of MV, survivors (days) & $5[3-13]$ & $5[3-8.5]$ & 0.13 \\
\hline Discharge home self-care & $37(31 \%)$ & $47(41 \%)$ & 0.15 \\
\hline Died in hospital & $30(25 \%)$ & $16(14 \%)$ & 0.026 \\
\hline
\end{tabular}

Acute kidney injury is defined as serum creatinine $\geq 2 \mathrm{mg} / \mathrm{dL}$ or urine output $<500 \mathrm{~mL} /$ day

Shock is defined as vasopressor use or mean arterial pressure $<60 \mathrm{mmHg}$ for two measurements

Abbreviations: ARDS acute respiratory distress syndrome, ICU intensive care unit; SOFA Sequential Organ Failure Assessment, CVP central venous pressure, RRT renal replacement therapy

${ }^{a}$ Data shown as $n(\%)$, mean (standard deviation) or median [inter-quartile range] if not normally distributed

${ }^{\mathrm{b}} p$ value for ICU type represents chi-square test for independence across ICU types

'Of patients who received diuretics in $48-72 \mathrm{~h}$ after ARDS, 108 (93\%) received furosemide

\section{Sensitivity analyses}

We conducted sensitivity analyses for the final model by sequentially excluding pre-specified sub-groups by patient factors and ICU types to confirm the association between diuretic use and mortality. By this method, we found no statistically significant difference in estimates of the association between diuretic use and mortality. Notably, the unadjusted association between diuretic use and mortality among patients without heart failure was of lesser magnitude $(n=135$; OR $0.90,95 \% \mathrm{CI}[0.37,2.14])$ than within the subgroup with heart failure $(n=99 ; 0.19[0.06,0.55])$.

When the analysis was limited only to those who remained alive and in the ICU after 7 days $(n=160)$ to exclude both the highest and lowest acuity patients, the association between diuretic use and outcome in the multivariable model was unchanged.

Table 2 Fluid Balance by diuretic exposure in $48-72 \mathrm{~h}$ after meeting acute respiratory distress syndrome criteria

\begin{tabular}{|c|c|c|c|}
\hline Patient characteristics ${ }^{\mathrm{a}}$ (units) & No diuretic in $48-72 \mathrm{~h}$ after ARDS & Received diuretic in $48-72 \mathrm{~h}$ after ARDS & $P$ value \\
\hline Pre-ARDS ICU fluid balance (total L) & $0.4[0-2.8]$ & $0.3[0-3.4]$ & 0.89 \\
\hline \multicolumn{4}{|l|}{ 0-48 $\mathrm{h}$ after ARDS: } \\
\hline Daily fluid balance (L/24 h) & $1.5[0.4-2.7]$ & $0.5[-0.7-1.7]$ & $<0.0001$ \\
\hline Crystalloid intake (L/24 h) & $1.2[0.6-2.5]$ & $0.6[0.1-1.4]$ & $<0.0001$ \\
\hline Medication fluid intake ( $L / 24 \mathrm{~h}$ ) & $1.1[0.8-1.7]$ & $1.1[0.7-1.8]$ & 0.92 \\
\hline Nutrition intake (L/24 h) & $0.5[0.1-1.1]$ & $0.5[0.2-1.0]$ & 0.86 \\
\hline Free water intake $(L / 24 \mathrm{~h})$ & $0.1[0-0.2]$ & $0.1[0-0.2]$ & 0.39 \\
\hline Transfusion intake (L/24 h) & $0[0-0.1]$ & $0[0-0.1]$ & 0.84 \\
\hline Total fluid output (L/24 h) & $2.2[1.4-3.4]$ & $2.7[1.9-3.4]$ & 0.042 \\
\hline Net ICU fluid balance at $48 \mathrm{~h}$ (total L) & $4.4[1.6-7.8]$ & $2.5[-1.0-6.6]$ & 0.0047 \\
\hline \multicolumn{4}{|l|}{ 48-72 $\mathrm{h}$ after ARDS: } \\
\hline Daily fluid balance (L/24h) & $0.6[-0.3-1.7]$ & $-0.9[-2.1-0.2]$ & $<0.0001$ \\
\hline Crystalloid intake (L/24 h) & $0.3[0-1.0]$ & $0[0-0.3]$ & 0.0007 \\
\hline Less than $500 \mathrm{~mL}$ in $24 \mathrm{~h}$ & $69(59 \%)$ & $84(72 \%)$ & 0.03 \\
\hline Free water intake (L/24 h) & $0[0-0.1]$ & $0[0-0.2]$ & 0.17 \\
\hline Medication fluid intake ( $L / 24$ h) & $0.9[0.5-1.5]$ & $1[0.5-1.6]$ & 0.6 \\
\hline Nutrition intake (L/24 h) & $0.9[0.2-1.5]$ & $1.1[0.4-1.6]$ & 0.42 \\
\hline Free water intake $(\mathrm{L} / 24 \mathrm{~h})$ & $0[0-0.1]$ & $0[0-0.2]$ & 0.17 \\
\hline Transfusion intake (L/24 h) & $0[0-0]$ & $0[0-0]$ & 0.05 \\
\hline Total fluid output (L/24 h) & $2.2[1.6-2.9]$ & $3.3[2.4-4.5]$ & $<.0001$ \\
\hline Net ICU fluid balance at $\mathbf{7 2} \mathbf{h}$ (Total L) & $5.3[1.6-9.4]$ & $1.6[-2.3-6.1]$ & $<0.0001$ \\
\hline
\end{tabular}

Volume overload is defined as a net ICU fluid balance (in L) equivalent to more than $10 \%$ of admission body weight (in $\mathrm{kg}$ )

Duration of MV refers to the duration in days of mechanical ventilation episode that includes ARDS onset

Abbreviations: ARDS acute respiratory distress syndrome, ICU intensive care unit

${ }^{a}$ Data shown as $n(\%)$, mean (standard deviation), or median [inter-quartile range] if not normally distributed 


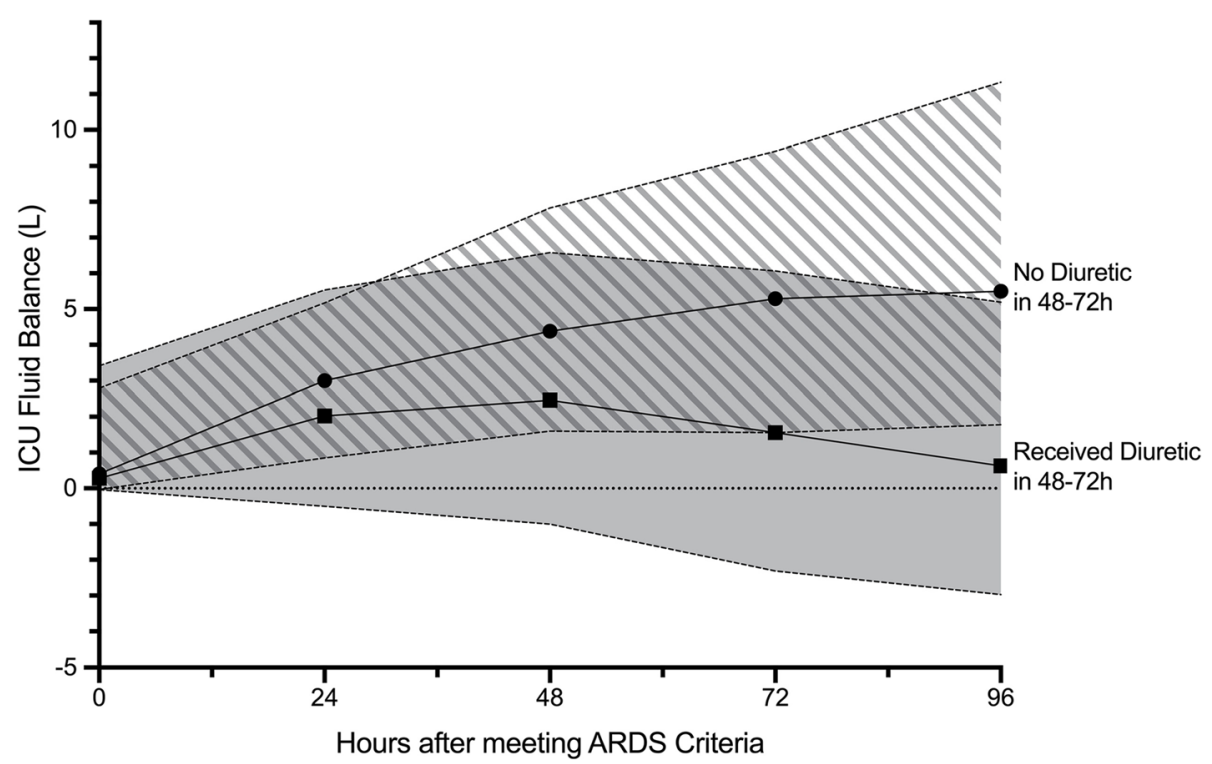

Fig. 2 Distribution of cumulative ICU fluid balances over time, comparing subjects who received a diuretic in hours 48-72 after meeting ARDS criteria ("Received diuretic", squares) with those who did not ("No diuretic", circles). Data points represent median values for each group, with associated bands representing inter-quartile ranges. For hours $0-72, n=234$. For hour $96, n=225$

\section{Discussion}

This investigation used retrospective data to assess whether early conservative fluid management with diuretics for ARDS is associated with improved outcomes and whether this relationship is independent of other patient and ICU factors. Our analysis demonstrates three important findings.

First, one-half of these ARDS patients received diuretic medications early, in 48 to $72 \mathrm{~h}$ after ARDS. We found this diuretic use was not associated with the protocol instructions used in FACTT. Second, volume overload was common and present early, with crystalloid fluids comprising a relatively small proportion of daily fluid intake. Third, early diuretic use in ARDS is associated with better outcomes, as the cohort that received diuretics had lower hospital mortality even after controlling for confounding clinical factors.

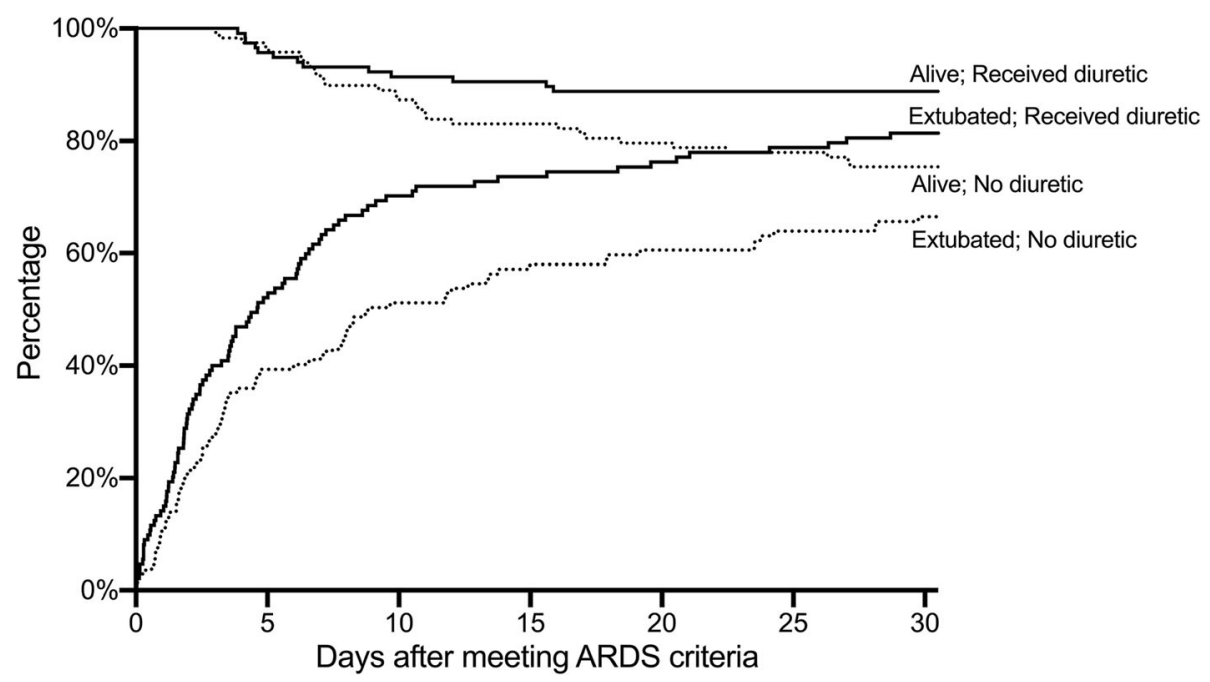

Fig. 3 Proportion of patients surviving to hospital discharge ("Alive") and proportion breathing without mechanical ventilation ("Extubated"), comparing subjects who received a diuretic during hours 48-72 after meeting ARDS criteria (solid line, "Received diuretic") with those who did not (dotted line "No diuretic"). Time points for breathing without mechanical ventilation, represent the times of final extubation from mechanical ventilation during the study hospitalization among patients who survived to discharge. Overall, 4 patients died more than 30 days after meeting ARDS criteria, and 16 patients survived to discharge without mechanical ventilation but were extubated more than 30 days after meeting ARDS criteria 
Table 3 Multivariable model for hospital mortality

\begin{tabular}{ll}
\hline Patient characteristics & Adjusted odds ratio $(\mathbf{9 5 \%} \mathbf{C l})$ \\
\hline Diuretics, 48-72 $\mathrm{h}$ after ARDS & $\mathbf{0 . 4 6}(\mathbf{0 . 2 2}, \mathbf{0 . 9 6})$ \\
Age, categorized & $\mathbf{1 . 8 3}(\mathbf{1 . 1 4}, \mathbf{2 . 9 5})$ \\
Congestive heart failure & $0.59(0.26,1.34)$ \\
Trauma as ARDS risk factor & $0.52(0.22,1.24)$ \\
SOFA score, at ARDS onset, categorized & $\mathbf{6 . 3 5}(\mathbf{1 . 9 1 , 2 1 . 1 3 )}$ \\
Volume overload at 48 $\mathrm{h}$ & $1.65(0.74,3.71)$
\end{tabular}

Age at admission was categorized into groups of $<55,55-70,70-80$, $>80$ years old.

SOFA score was categorized into groups of $\leq 8,>8$ and $\leq 16$, and $>16$ for a linear association with mortality

Volume overload is defined as a net ICU fluid balance (in L) equivalent to more than $10 \%$ of admission body weight (in $\mathrm{kg}$ )

Abbreviations: ARDS acute respiratory distress syndrome, SOFA Sequential Organ Failure Assessment Score

\section{Comparison with previous studies}

Volume overload is associated with organ failure and is recognized as an independent predictor of poor outcomes [19, 21, 23-25]. Increasing evidence demonstrates that restrictive fluid strategies including diuresis may be associated with better outcomes, particularly in critical illness and ARDS [10, 17, 26-29]. To our knowledge, this is the first study to characterize fluid balance and diuretic use in usual care for ARDS patients since Wiedemann and colleagues published the landmark trial, FACTT, in 2006 [11]. Of patients with ARDS that were screened for FACTT, 91.3\% $(10,511 / 11,512)$ were excluded. In contrast, to reflect usual care, we excluded only those already on dialysis and those who were ineligible for our exposure of interest.

FACTT compared a conservative and a liberal fluid management protocol in ARDS patients, with the conservative arm receiving more diuretic medications and less crystalloid. The trial demonstrated a benefit to the conservative protocol in lung function, duration of mechanical ventilation, and ICU stay. Our findings also suggest benefit from early conservative fluid management. Notably, FACTT did not find a mortality difference attributable to the fluid management strategy, where our analysis found a strong association. This difference may be explained by the FACTT protocol instructions that provided multiple criteria for not giving diuretics in the conservative arm, where all patients in our exposed group received diuretics.

On day 2 after enrollment in FACTT, 60\% of subjects in the conservative arm of the trial received furosemide, while $29 \%$ did in the liberal arm. In our study population, $50 \%$ overall received a dose of diuretic. The clinical trial achieved a $4.7 \mathrm{~L}$ separation in the mean net fluid balance between each arm, while the two groups in our cohort had a difference of $3.7 \mathrm{~L}$ in median ICU fluid balance at a comparable time point of $72 \mathrm{~h}$ from ARDS onset.

In contrast to the study population of FACTT, we only included patients with moderate-severe ARDS defined by a $\mathrm{PaO}_{2}: \mathrm{FiO}_{2}$ ratio of less than 150 , where FACTT included all ARDS patients with a ratio less than 300. Our cohort was similar in age to the population enrolled in FACTT (mean ages 55 and 50 years, respectively) and observed mortality (20 and 27\%). While all FACTT care protocols required CVP or PAOP values, these measurements were rarely used in our cohort, with only $18 \%$ having any CVP documented during ARDS hours 48 to 72 . Finally, FACTT excluded many ARDS patients such as those with chronic lung disease or severe cirrhosis, and its protocol withheld diuretics from those with shock, with a normal CVP, or renal failure. We found no difference in the management of patients by these factors, demonstrating that they are not clinical exclusions to diuretic use in usual care. The benefits of conservative fluid management and the use of diuretics may be generalizable to these populations, which would be consistent with clinician surveys and observational studies [30-32].

Prior studies have demonstrated that most fluids administered in critical care are given with medications rather than as bolus or maintenance crystalloid [33, 34]. Our study corroborates these findings that crystalloid used for resuscitation is typically a less significant contributor to net fluid balance than diuretic use and incidental fluids in the ARDS population [29, 35-38].

Gaps in implementation of evidence from randomized controlled trials into routine care for ARDS have been demonstrated previously by the inconsistent use of low tidal volume ventilation or prone positioning [3, 39-41]. Early attention to fluids and diuresis may represent another implementation gap from under-recognition of ARDS or from missed opportunities to provide early conservative fluid management in standard practice.

\section{Study limitations}

There are several potential limitations to this study. Confounding by indication poses the largest threat to the validity of this analysis. We do not have direct measures of clinical decision-making for diuretic use in usual care. CVP or PAOP criteria were used to guide management in both the FACTT and FACTT Lite study protocols, but these measurements were rarely available in our ARDS population $[11,16]$. Fluid balance may affect diuretic use and outcomes, so we conducted sensitivity analyses and included volume overload as a confounder in the multivariable model. Variability in opinion exists among providers on the best methods for volume status assessments and fluid management decisions, suggesting a likely source of provider-level variability [31, 42]. Nevertheless, the groups of patients may have had other unmeasured confounders responsible for the difference in outcomes.

We identified a cohort with moderate-severe ARDS to reflect current clinical practice and ongoing clinical trials, but heterogeneity among ARDS patients certainly 
exists and effect modification may be present in influential sub-groups [43-45]. Sensitivity analyses did not identify any groups with significantly different benefits or harm in this sample, but this study was underpowered to detect meaningful associations within sub-groups. A strong association exists between diuretic use and mortality in the sub-group enriched for congestive heart failure, while considerable uncertainty exists in the estimate for the group without heart failure. We have no direct measurement of left atrial pressures in this observational study, but data collected in FACTT demonstrated no association between elevated left atrial pressure and outcomes $[46,47]$. These findings are a further demonstration of the abundance of comorbidities like heart failure in the ARDS population, and emerging research may better identify distinct disease processes combined into this cohort.

Our exposure of interest was receiving diuretics during a 24-h sample time period, but one dose is not expected to have a direct causal effect on mortality. Rather, this measure serves as a marker for early attention to conservative fluid management and diuresis. Receiving diuretics during this time is highly correlated with additional use across the ICU course. Of those patients who received a diuretic in 48 to $72 \mathrm{~h}$ after ARDS, $74 \%$ (86/116) also received a dose during the following day (72 to $96 \mathrm{~h}$ ), compared with only $25 \%(29 / 118)$ of the other group. We found that the use of this dichotomous variable at an early time point effectively captures an eligible cohort and simplifies the assessment and differentiation of groups while minimizing the multiple comparisons of longitudinal analyses.

Fluid balance was an important covariate in this retrospective study, but it was subject to multiple sources of bias. The assessments of fluid intake and output were limited to data that were documented in the electronic medical record. As a consequence, patients who had an output that was challenging to quantify, like blood or gastrointestinal losses, were at risk for measurement bias, as were those who visited the operating rooms, where fluid balance documentation may be different from standard practice in the ICU. Additionally, we defined volume overload as a cumulative ICU fluid balance greater than $10 \%$ of the earliest body weight recorded during the hospital encounter, based on prior published research from our institution [21]. Some patient weights, however, may have been measured inaccurately or after initial fluid resuscitation, which could have led to misclassification of volume overload status.

Finally, this study was conducted at two hospitals in the same city, which limits the generalizability due to local clinician practice patterns and ICU populations with a relatively high proportion of trauma as an ARDS risk factor.

\section{Conclusions}

This study is an important contribution to the literature on fluid management in ARDS. We demonstrate that the use of diuretic medications in this cohort is a highly variable practice that is associated with outcomes. Our analysis provides insight and support for active fluid stewardship in most ARDS patients. Increasing the prevention, recognition, and early treatment of volume overload in ARDS patients may be key implementation opportunities to improve outcomes for patients with ARDS. These observations can also inform an interventional study, to determine the impact of reducing variability for ARDS care and standardizing fluid management with active diuresis as a target.

Among patients with ARDS, volume overload is common and present early. Most patients accumulate a positive net fluid balance after meeting ARDS criteria, driven by fluid intake from sources other than crystalloid. Early diuretic use after meeting ARDS criteria is independently associated with lower hospital mortality.

\section{Supplementary information}

Supplementary information accompanies this paper at https://doi.org/10. 1186/s40560-020-00496-7.

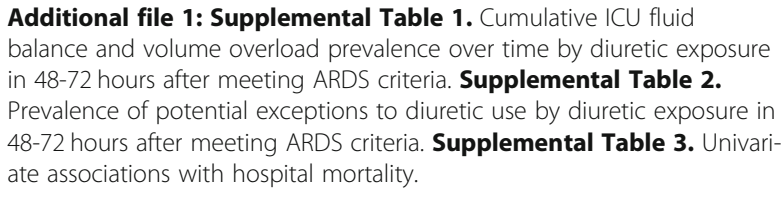

Additional file 1: Supplemental Table 1. Cumulative ICU fluid balance and volume overload prevalence over time by diuretic exposure in 48-72 hours after meeting ARDS criteria. Supplemental Table 2.

Prevalence of potential exceptions to diuretic use by diuretic exposure in 48-72 hours after meeting ARDS criteria. Supplemental Table 3. Univariate associations with hospital mortality.

\section{Abbreviations \\ AKI: Acute kidney injury; ARDS: Acute respiratory distress syndrome; \\ CVP: Central venous pressure; FACTT: Fluid and Catheters Treatment Trial; \\ $\mathrm{FiO}_{2}$ : Fraction of inspired oxygen; ICU: Intensive care unit; PAOP: Pulmonary artery occlusion pressure; $\mathrm{PaO}_{2}$ : Partial pressure of oxygen in arterial blood; SOFA: Sequential Organ Failure Assessment}

\section{Acknowledgements}

Not applicable.

\section{Authors' contributions}

KPS and CLH conceptualized and designed the study; KPS, ESC, and CLH acquired, analyzed, and interpreted the data; KPS drafted the manuscript; KPS, ESC, and CLH revised the manuscript. All authors read and approved the final manuscript.

\section{Funding}

Dr. Hough is supported in part by K24HL141526 (PI: Hough) from the National Institutes of Health / National Heart, Lung, and Blood Institute.

\section{Availability of data and materials}

The datasets used and/or analyzed during the current study are available from the corresponding author on reasonable request.

\section{Ethics approval and consent to participate}

The institutional review board at the University of Washington reviewed and approved this study, waiving the need for informed consent.

Consent for publication

Not applicable. No details, images, or videos relating to an individual person. 


\section{Competing interests}

The authors declare that they have no competing interests.

\section{Author details}

'Division of Pulmonary, Allergy, and Critical Care Medicine, Vanderbilt University, Nashville, TN, USA. ${ }^{2}$ Vanderbilt University Medical Center, T1218 MCN, 1161 21st Avenue, Nashville, TN 37232, USA. ㄹ. Division of Pulmonary and Critical Care Medicine, University of Washington, Seattle, WA, USA. ${ }^{4}$ Division of Pulmonary and Critical Care Medicine, Oregon Health and Science University, Portland, OR, USA.

Received: 18 June 2020 Accepted: 25 September 2020

Published online: 12 October 2020

\section{References}

1. Rubenfeld GD, Caldwell E, Peabody E, et al. Incidence and outcomes of acute lung injury. N Engl J Med. 2005;353(16):1685-93. https://doi.org/10. 1056/NEJMoa050333.

2. ARDS Definition Task Force, Ranieri VM, Rubenfeld GD, et al. Acute respiratory distress syndrome: the Berlin definition. JAMA. 2012;307(23): 2526-33. https://doi.org/10.1001/jama.2012.5669.

3. Bellani G, Laffey JG, Pham T, et al. Epidemiology, patterns of care, and mortality for patients with acute respiratory distress syndrome in intensive care units in 50 countries. JAMA. 2016;315(8):788-800. https://doi.org/10. 1001/jama.2016.0291.

4. Pham T, Rubenfeld GD. Fifty years of research in ards the epidemiology of acute respiratory distress syndrome a 50th birthday review. Am J Respir Crit Care Med. 2017;195(7):860-70. https://doi.org/10.1164/rccm.201609-1773CP.

5. Simmons RS, Berdine GG, Seidenfeld JJ, et al. Fluid balance and the adult respiratory distress syndrome. Am Rev Respir Dis. 1987;135(4):924-9 http:// www.ncbi.n/m.nih.gov/pubmed/3565940.

6. Sakr $Y, B C h$ M, Vincent J-L, et al. High tidal volume and positive fluid balance are associated with worse outcome in acute lung injury*. Chest 2005;128:3098-108. https://doi.org/10.1378/chest.128.5.3098.

7. Rosenberg AL, Dechert RE, Park PK, Bartlett RH, NIH NHLBI ARDS Network. Review of a large clinical series: association of cumulative fluid balance on outcome in acute lung injury: a retrospective review of the ARDSnet tidal volume study cohort. J Intensive Care Med. 24(1):35-46. https://doi.org/10. $1177 / 0885066608329850$.

8. Murphy CV, Schramm GE, Doherty JA, et al. The importance of fluid management in acute lung injury secondary to septic shock. Chest. 2009; 136(1):102-9. https://doi.org/10.1378/chest.08-2706.

9. Jozwiak $M$, Silva S, Persichini $R$, et al. Extravascular lung water is an independent prognostic factor in patients with acute respiratory distress syndrome. Crit Care Med. 2013:41(2):472-80. https://doi.org/10.1097/CCM. Ob013e31826ab377.

10. Silversides JA, Major E, Ferguson AJ, et al. Conservative fluid management or deresuscitation for patients with sepsis or acute respiratory distress syndrome following the resuscitation phase of critical illness: a systematic review and meta-analysis. Intensive Care Med. 2017;43(2):155-70. https://doi. org/10.1007/s00134-016-4573-3.

11. The National Heart, Lung and BIARDS (ARDS) CTN. Comparison of two fluidmanagement strategies in acute lung injury. N Engl J Med. 2007;51(5):22930. https://doi.org/10.1097/sa.0b013e318149f920.

12. Rhodes A, Evans LE, Alhazzani W, et al. Surviving sepsis campaign: international guidelines for management of sepsis and septic shock: 2016. Crit Care Med. 2017:45(3):486-552. https://doi.org/10.1097/CCM. 0000000000002255 .

13. Bein T, Grasso S, Moerer O, et al. The standard of care of patients with ARDS: ventilatory settings and rescue therapies for refractory hypoxemia. Intensive Care Med. 2016;42(5):699-711. https://doi.org/10.1007/s00134-0164325-4.

14. Griffiths MJD, McAuley DF, Perkins GD, et al. Guidelines on the management of acute respiratory distress syndrome. BMJ Open Respir Res. 2019;6(1): e000420. https://doi.org/10.1136/bmjresp-2019-000420.

15. Casey JD, Semler MW, Rice TW. Fluid management in acute respiratory distress syndrome. Semin Respir Crit Care Med. 2019;40(1):57-65. https://doi. org/10.1055/s-0039-1685206.

16. Grissom CK, Hirshberg EL, Dickerson JB, et al. Fluid management with a simplified conservative protocol for the acute respiratory distress syndrome*. Crit Care Med. 2015;43(2):288-95. https://doi.org/10.1097/CCM. 0000000000000715.

17. Cordemans C, De Laet I, Van Regenmortel N, et al. Aiming for a negative fluid balance in patients with acute lung injury and increased intraabdominal pressure: a pilot study looking at the effects of PAL-treatment. Ann Intensive Care. 2012;2(Suppl 1):S15. https://doi.org/10.1186/2110-58202-S1-S15.

18. Vincent JL, Moreno R, Takala J, et al. The SOFA (Sepsis-related Organ Failure Assessment) score to describe organ dysfunction/failure. On behalf of the Working Group on Sepsis-Related Problems of the European Society of Intensive Care Medicine. Intensive Care Med. 1996;22(7):707-10. https://doi. org/10.1007/bf01709751

19. Vincent J-L, Sakr $Y$, Sprung $C L$, et al. Sepsis in European intensive care units: results of the SOAP study. Crit Care Med. 2006;34(2):344-53. https://doi.org/ 10.1097/01.ccm.0000194725.48928.3a.

20. Balakumar V, Murugan R, Sileanu FE, Palevsky P, Clermont G, Kellum JA. Both positive and negative fluid balance may be associated with reduced long-term survival in the critically ill. Crit Care Med. 2017;45(8):e749-57. https://doi.org/10.1097/CCM.0000000000002372.

21. Mitchell KH, Carlbom D, Caldwell E, Leary PJ, Himmelfarb J, Hough CL. Volume overload: prevalence, risk factors, and functional outcome in survivors of septic shock. Ann Am Thorac Soc. 2015;12(12):1837-44. https:// doi.org/10.1513/AnnalsATS.201504-1870C.

22. Bouchard J, Soroko SB, Chertow GM, et al. Fluid accumulation, survival and recovery of kidney function in critically ill patients with acute kidney injury. Kidney Int. 2009;76(4):422-7. https://doi.org/10.1038/ki.2009.159.

23. Kelm DJ, Perrin JT, Cartin-Ceba R, Gajic O, Schenck L, Kennedy CC. Fluid overload in patients with severe sepsis and septic shock treated with early goal-directed therapy is associated with increased acute need for fluidrelated medical interventions and hospital death. Shock. 2015:43(1):68-73. https://doi.org/10.1097/SHK.0000000000000268.

24. Neyra JA, Li X, Canepa-Escaro F, et al. Cumulative fluid balance and mortality in septic patients with or without acute kidney injury and chronic kidney disease. Crit Care Med. 2016;44(10):1891-900. https://doi.org/10.1097/ CCM.0000000000001835

25. Lee J, De Louw E, Niemi M, et al. Association between fluid balance and survival in critically ill patients HHS Public Access. J Intern Med. 2015;277(4): 468-77. https://doi.org/10.1111/joim.12274.

26. Finfer S, Myburgh J, Bellomo R. Intravenous fluid therapy in critically ill adults. Nat Rev Nephrol. 2018;14(9):541-57. https://doi.org/10.1038/s41581018-0044-0.

27. Malbrain MLNG, Marik PE, Witters I, et al. Fluid overload, de-resuscitation, and outcomes in critically ill or injured patients: a systematic review with suggestions for clinical practice. Anaesthesiol Intensive Ther. 2014;46(5):36180. https://doi.org/10.5603/AIT.2014.0060.

28. Dessap AM, Roche-Campo F, Kouatchet A, et al. Natriuretic peptide-driven fluid management during ventilator weaning: a randomized controlled trial. Am J Respir Crit Care Med. 2012;186(12):1256-63. https://doi.org/10.1164/ rccm.201205-09390C.

29. Silversides JA, Fitzgerald E, Manickavasagam US, et al. Deresuscitation of patients with iatrogenic fluid overload is associated with reduced mortality in critical illness. Crit Care Med. 2018;46(10):1600-7. https://doi.org/10.1097/ CCM.0000000000003276

30. Shen Y, Zhang W, Shen Y. Early diuretic use and mortality in critically ill patients with vasopressor support: a propensity score-matching analysis 11 Medical and Health Sciences 1103 Clinical Sciences. Crit Care. 2019;23(1) https://doi.org/10.1186/s13054-019-2309-9.

31. Silversides JA, MCAuley DF, Blackwood B, Fan E, Ferguson AJ, Marshall JC. Fluid management and deresuscitation practices: a survey of critical care physicians. J Intensive Care Soc. 2019:175114371984644. https://doi.org/10. 1177/1751143719846442.

32. Bandak G, Sakhuja A, Andrijasevic NM, Gunderson TM, Gajic O, Kashani K. Use of diuretics in shock: temporal trends and clinical impacts in a propensity-matched cohort study. PLoS One. 2020;15(2):e0228274. https:// doi.org/10.1371/journal.pone.0228274.

33. Magee CA, Bastin MLT, Laine ME, et al. Insidious harm of medication diluents as a contributor to cumulative volume and hyperchloremia: a prospective, open-label, sequential period pilot study. Crit Care Med. 2018; 46(8):1217-23. https://doi.org/10.1097/CCM.0000000000003191.

34. Van Regenmortel N, Verbrugghe W, Roelant E, Van Den Wyngaert T, Jorens PG. Maintenance fluid therapy and fluid creep impose more significant fluid, 
sodium, and chloride burdens than resuscitation fluids in critically ill patients: a retrospective study in a tertiary mixed ICU population. Intensive Care Med. 2018;44:409-17. https://doi.org/10.1007/s00134-018-5147-3.

35. Finfer S, Liu B, Taylor C, et al. Resuscitation fluid use in critically ill adults: an international cross-sectional study in 391 intensive care units. Crit Care. 2010;14(5):R185. https://doi.org/10.1186/cc9293.

36. Bihari S, Prakash S, Bersten AD. Post resusicitation fluid boluses in severe sepsis or septic shock: prevalence and efficacy (price study). Shock. 2013; 40(1):28-34. https://doi.org/10.1097/SHK.0b013e31829727f1.

37. Glassford NJ, Mårtensson J, Eastwood GM, et al. Defining the characteristics and expectations of fluid bolus therapy: a worldwide perspective. J Crit Care. 2016;35(6):126-32. https://doi.org/10.1016/j.jcrc.2016.05.017.

38. Bissell BD, Laine ME, Thompson Bastin ML, et al. Impact of protocolized diuresis for de-resuscitation in the intensive care unit. Crit Care. 2020;24(1): 1-10. https://doi.org/10.1186/s13054-020-2795-9.

39. Spece LJ, Mitchell KH, Caldwell ES, Gundel SJ, Jolley SE, Hough CL. Low tidal volume ventilation use remains low in patients with acute respiratory distress syndrome at a single center. J Crit Care. 2018;44:72-6. https://doi. org/10.1016/j.jcrc.2017.10.021.

40. Fröhlich S, Murphy N, Doolan A, Ryan O, Boylan J. Acute respiratory distress syndrome: underrecognition by clinicians. J Crit Care. 2013;28(5):663-8. https://doi.org/10.1016/j.jcrc.2013.05.012

41. Guérin $\mathrm{C}$, Beuret $\mathrm{P}$, Constantin JM, et al. A prospective international observational prevalence study on prone positioning of ARDS patients: the APRONET (ARDS Prone Position Network) study. Intensive Care Med. 2018; 44(1):22-37. https://doi.org/10.1007/s00134-017-4996-5.

42. O'Connor ME, Jones SL, Glassford NJ, Bellomo R, Prowle JR. Defining fluid removal in the intensive care unit: a national and international survey of critical care practice. J Intensive Care Soc. 2017;18(4):282-8. https://doi.org/ 10.1177/1751143717699423.

43. Semler MW, Marney AM, Rice TW, et al. B-Type natriuretic peptide, aldosterone, and fluid management in ARDS. Chest. 2016. https://doi.org/10 1016/j.chest.2016.03.017.

44. Famous KR, Delucchi K, Ware LB, et al. Acute respiratory distress syndrome subphenotypes respond differently to randomized fluid management strategy. Am J Respir Crit Care Med. 2017. https://doi.org/10.1164/rccm. 201603-06450C

45. Semler MW, Wheeler AP, Thompson BT, Bernard GR, Wiedemann HP, Rice TW. Impact of initial central venous pressure on outcomes of conservative versus liberal fluid management in acute respiratory distress syndrome. Crit Care Med. 2016. https://doi.org/10.1097/CCM.0000000000001555.

46. National Heart, Lung and BIARDS (ARDS) CTN, Wheeler AP, Bernard GR, et al. Pulmonary-artery versus central venous catheter to guide treatment of acute lung injury. N Engl J Med. 2006;354(21):2213-24. https://doi.org/10. 1056/NEJMoa061895.

47. Bull TM, Clark B, McFann K, Moss M. Pulmonary vascular dysfunction is associated with poor outcomes in patients with acute lung injury. Am J Respir Crit Care Med. 2010;182(9):1123-8. https://doi.org/10.1164/rccm. 201002-02500C

\section{Publisher's Note}

Springer Nature remains neutral with regard to jurisdictional claims in published maps and institutional affiliations.

Ready to submit your research? Choose BMC and benefit from:

- fast, convenient online submission

- thorough peer review by experienced researchers in your field

- rapid publication on acceptance

- support for research data, including large and complex data types

- gold Open Access which fosters wider collaboration and increased citations

- maximum visibility for your research: over $100 \mathrm{M}$ website views per year

At BMC, research is always in progress.

Learn more biomedcentral.com/submissions 